\title{
Emergency Management Planning in COVID-19 Pandemic Period
}

\author{
Edip Burak Karaaslan, (D) Serenay Kandur, (D) İrem Kirkizoğlu, (D) Asım Kalkan
}

Prof. Dr. Cemil Taşçıoğlu City Hospital, Clinic of Emergency Medicine, İstanbul, Turkey

\section{Abstract}

Coronavirus Disease-2019 was first reported in the city of Wuhan, Hubei Province of China, and has spread worldwide. The World Health Organization reported that this epidemic is a global public health problem. In our country, the first case was reported on March 11, 2020. Many changes were made in our hospital. We made one of the most radical changes in our emergency room. These changes included both work plan and physical changes. We think that these changes will be a guide in the later pandemic periods.

Keywords: COVID-19, pandemic, emergency department, management

\section{INTRODUCTION}

Coronavirus Disease-2019 (COVID-19) was first reported in Wuhan city of Hubei Province of China, and today it has spread all over the world (1). The disease spread around the world, and on March 11, 2020, the World Health Organization (WHO) reported that the outbreak became a pandemic (2). In our country, the first patient was reported by the ministry of health on March 11, 2020. Until this date, many measures were taken early against the disease seen in many surrounding countries. At our hospital, we have taken many safety measures in all departments ranging from the hospital administration department to the smallest department and have made some changes. The most radical changes were made in our emergency department. These changes have included both work plans and physical changes. For this reason, we believe that defining these changes along with the reasoning behind them will be fundamental in later pandemic periods.

\section{Physical Changes}

Since COVID-19 is a respiratory and contact disease, pre-hospital planning should be at the forefront. The emergency service of our hospital was divided into two areas, clean and dirty. The triage area established in front of emergency services was designated to welcome all incoming patients. The patients were divided into two groups, those with suspected COVID-19 and those without suspected COVID-19, per recommendations from the ministry of health. Suspected patients were taken into the hospital through a separate door and those without suspected disease through another separate door. The area where patients with suspected COVID-19 were taken was named as the dirty area. These patients had a high fever and cough, had contact with people from abroad in the first days of the disease entering our country, or were abroad in the last 14 days. On days when the number of our patients increased, patients with fever, cough, or shortness of breath were directed to the dirty area without seeking foreign contact (3). Let's define these areas now.

\section{Contagious Area}

Patients are guided from the triage area to the dirty area. The first application to be applied to patients with symptoms specified in the triage area is to wear a surgical mask. Vital signs such as fever, arterial blood pressure, pulse, and saturation are measured immediately afterward. Subsequently, patients who receive the triage card are directed to the dirty area. The entrance to the dirty area is from the outside. Patients are directed to the outside clinic for examination with two security guards and a nurse at the door.
Address for Correspondence: Asım Kalkan, Prof. Dr. Cemil Taşçıŏlu City Hospital, Clinic of Emergency Medicine, İstanbul, Turkey

Phone: +90 5337370934 E-mail: drasimkalkan@hotmail.com ORCID ID: orcid.org/0000-0002-5800-0201 Pandemic Period. Eur Arch Med Res 2020;36(Suppl 1):26-9

๑Copyright 2020 by the University of Health Sciences Turkey, Prof. Dr. Cemil Taşçığlu City Hospital European Archives of Medical Research published by Galenos Publishing House. 
There are three examination rooms, one resuscitation room, and one observation room in the dirty area. Patients who are referred to our hospital by ambulance are taken to the resuscitation room. There is an ambient sterilization device in this room to clean the air. This device filters the dirty air in the room and releases it back into the environment. In this way, the virus load to which people will be exposed to is reduced.

A section should be created in the observation vicinity for patient blood sample collection in the dirty area. Outpatients should be taken to the waiting room with at least 1-2 meters between them after their blood sample is collected. The waiting room should be constantly ventilated. Blood sample collection, electrocardiography, or treatment should be performed at the bedside of patients whose general condition is between moderate to poor. Computed tomography of the thorax, as well as the reverse transcriptase-polymerase chain reaction test, are useful for diagnosis in COVID-19 disease (4). Tomography scans of these patients should be performed by taking precautions. Patients should not come into contact with other patients while being transferred to the radiology unit. For this, we use a separate corridor in our hospital while transferring the patients. Masks and gloves must be worn during the transfer of the patients. If intubated patients have to go by ambulance, an effective filter against both bacteria and viruses should be connected to an Ambu $^{\circledR}$ mask.

\section{Clean Area}

The physical conditions of the clean area do not differ from the conditions before the COVID-19 pandemic. Surgical masks should be worn only by patients who come or are brought to this area. The clean area consists of three parts, clean green, yellow, and red areas. Patients who are thought not to have COVID-19 as a result of the triage performed in front of the clean green area are taken in for necessary examination. Patients who need to go from the green area to the yellow area should be taken to the yellow or red area without coming into contact with the dirty area. Those who need to be hospitalized among the patients who have undergone the necessary examinations and tests should be hospitalized in beds reserved as clean areas in the hospital in consultation with the relevant departments. Meanwhile, resuscitation equipment should be complete in each clean area. We manage our clean area in our hospital by taking all the precautions mentioned above.

\section{Changes in Work Plan}

Staff working in pandemics should be exposed to the virus load as little as possible. For this, it is very important to use personal protective clothing carefully, especially during working hours. One of the best measures to reduce the virus load is to reduce working hours. In addition, the importance of shift work in terms of employee health and comfort should not be overlooked. We have started to work in shifts in the emergency department of our hospital. We have created 12-hour shifts in the dirty area of our emergency department. Although some publications indicate that an 8-hour shift would be more appropriate, this should be shaped according to the number of staff in the hospital (5).

\section{Contagious Area}

We have adjusted the working order in two shifts in the dirty area. A total of four physicians, two of whom are experts and two of whom are assistants, have worked in each shift. According to the patient volume, these physicians have been recommended to work in groups of two among themselves. The physicians who have worked for two hours have been allowed to rest for two hours. Thus, a physician works for about 6 hours a day. Physicians have been allowed to rest for at least 3 days between their duties. A specialist physician has been appointed in the field of resuscitation in the dirty area. The main reason for this is to prevent loss of time in difficult intubations. Video laryngoscope should be used first while performing intubation in line with the current literature and experience (6). We have also used a video laryngoscope during intubation in our hospital. We have placed an application that we guess to be overlooked by many physicians, into our routine practice. Namely, clamping the tip of the intubation tube before intubation reduces virus aerosolization. It is necessary to post important warnings in the form of instructions in the resuscitation room and attract the attention of the physician. Intubation should be performed in a closed area called the respiratory protection unit where the patient's body is located. There are ready-made stretcher-shaped units, as well as a closed unit that the hospital can make with its own means (Figure 1) (7). These units should be transparent and we should be able to see all the procedures we will do to the patient from the outside. Intubation can be performed with the video laryngoscope by inserting hands through two holes on the part of the unit over the head of the patient. We also use a protection unit in our hospital that we have built with our own means. It should not be forgotten that virus filters are attached to the end of the intubation tubes of intubated patients. Video laryngoscopes to be used in this pandemic should also have some features. The current video laryngoscopes are of two types, the first one is mounted on a small monitor laryngoscope. In the second, the monitor is larger than the laryngoscope. The second video laryngoscope is more suitable for use in this pandemic. Because it is easier to use and provides less approach to the 


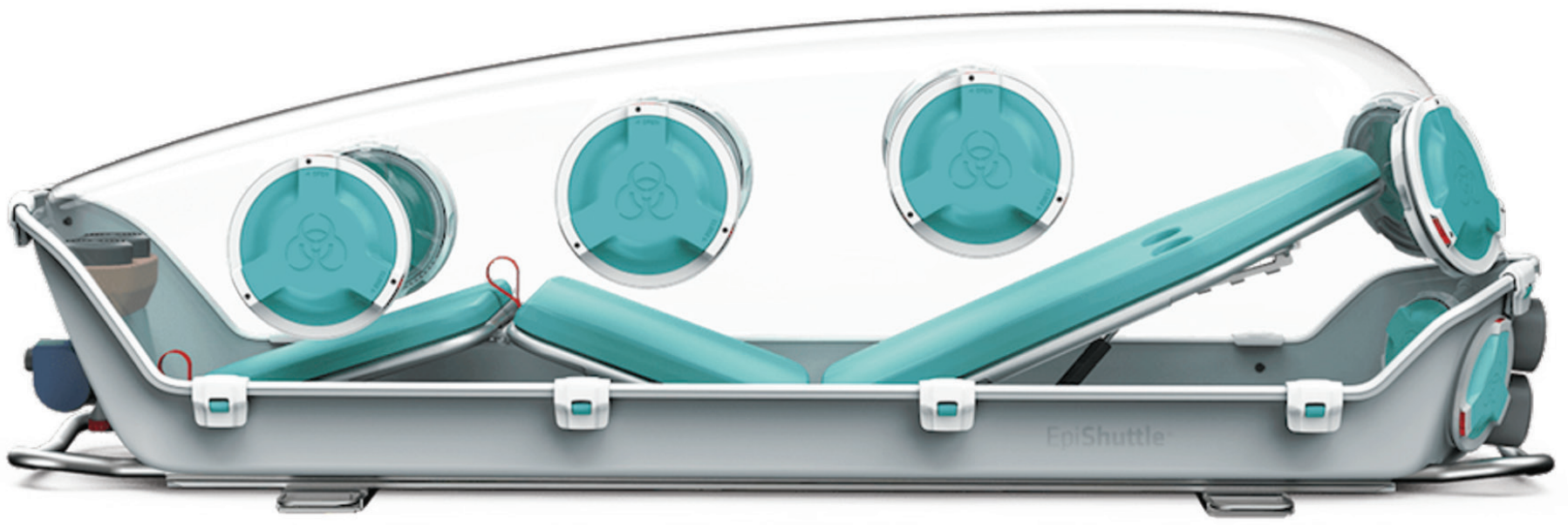

Figure 1. Completely closed stretcher with openings on the front and sides for patient intervention

patient. We use the second type of video laryngoscope in our hospital (Figure 2).

Transfer of intubated patients to the intensive care unit should also be done through a separate corridor and in closed units. Thus, virus aerosolization will be prevented.

It is necessary to make the nurses and allied health personnel work in shifts. The number of nurses working in the dirty area has been increased. According to patient volume, 12 or more nurses have been placed in each shift. The nurses, like physicians, have been allowed to work at 2-hour intervals. Two personnel shifting every 2 hours have been set to deal with patient services. These personnel have also been provided with personal protective clothing while working in the dirty area. Of course, all personnel have been trained in their work before moving on to this working order. In particular, we think that the training to be given to the allied health personnel in advance is very important in terms of reducing virus transmission.

\section{Clean Area}

Before the pandemic, the patient volume in yellow and red areas was very high. Since it has been thought that the number of patients coming to these areas will decrease with the pandemic, the number of working physicians has been reduced. Working hours in these areas have been set as 24 hours. Although there is no study on this subject yet, we have thought that there would be problems about consultation in these areas. The main reason for this is that all physicians would be on duty in COVID-19 patient wards. Normally, all departments are on duty in teams in our hospital. This problem has been overcome by decreasing the number of teams and placing an on-duty physician every day. We think

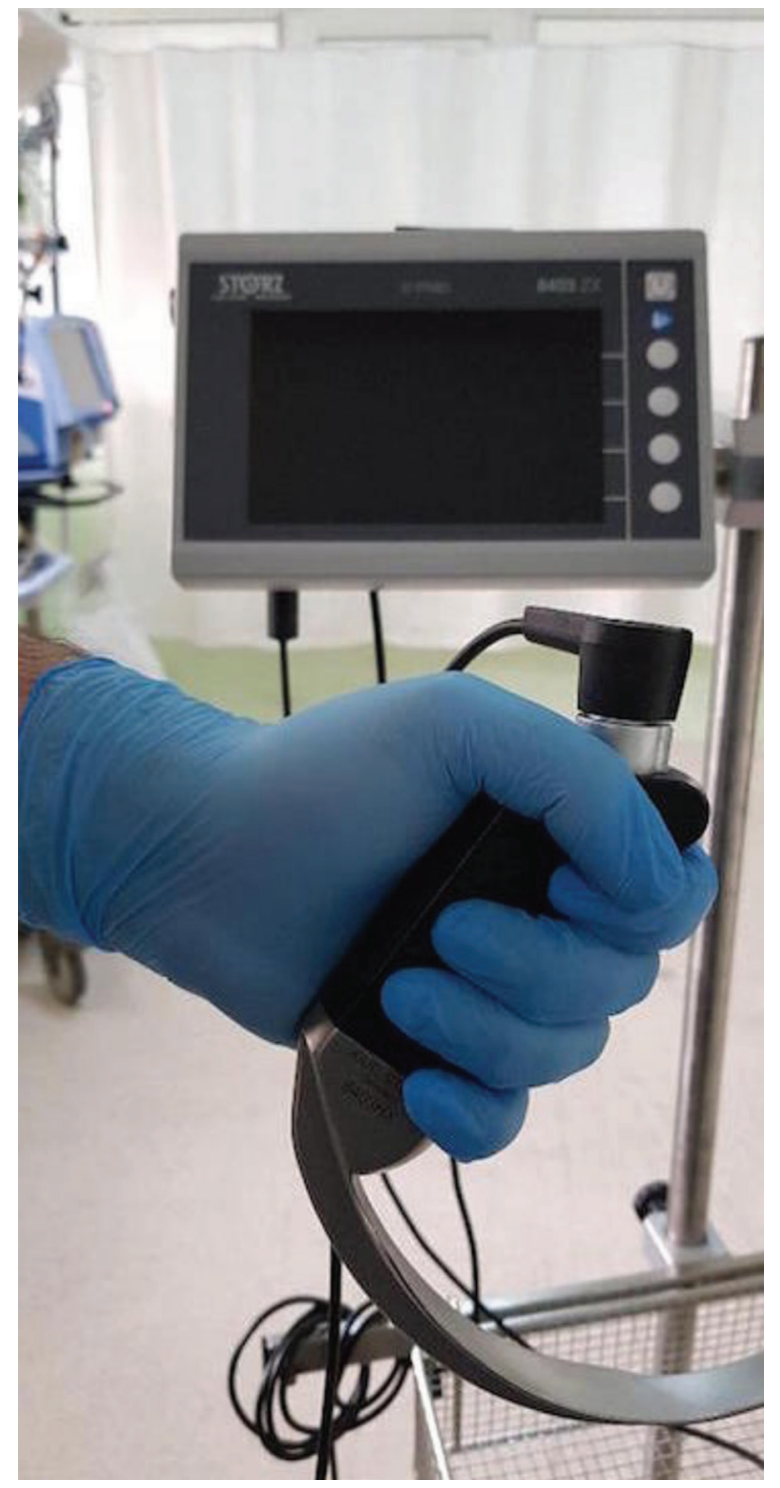

Figure 2. Video laryngoscope with monitor separate from laryngoscope 
that every hospital should arrange a consultant physician duty list according to its internal dynamics.

\section{CONCLUSION}

As a result, we have made arrangements for work in the emergency department of our hospital accordingly and have accelerated patient evaluation and hospitalization. The number of our patients, which was around 40,000 between February 11, 2020, and March 11, 2020, before the pandemic, decreased to 26,000 between March 11 and April 11, 2020. However, from March 11 to the beginning of May 2020, we consulted approximately 8,000 patients to the infectious diseases clinic. The main reason for the decrease in the number of patients can be attributed to the protective measures taken by the ministry of health. As a last word, we think that every hospital should make its own management plan according to its internal dynamics and physical conditions.

\section{Ethics}

Peer-review: Externally and internally peer-reviewed.

\section{Authorship Contributions}

Concept: A.K., Design: E.B.K., I.K., A.K., Data Collection or Processing: E.B.K., S.K., I.K., Analysis or Interpretation: S.K., I.K., Literature Search: E.B.K., S.K., I..K., Writing: A.K.
Conflict of Interest: No conflict of interest was declared by the authors.

Financial Disclosure: The authors declared that this study received no financial support.

\section{REFERENCES}

1. Zhu N, Zhang D, Wang W, Li X, Yang B, Song J, et al. A Novel Coronavirus from Patients with Pneumonia in China, 2019. N Engl J Med 2020;382:727-33

2. World Health Organization (2020). Coronavirus disease 2019 (COVID-19) situation report-39. World Health Organization, Geneva. Available from: URL: https://www.who.int/docs/default-source/coronaviruse/ situation-reports/20200228-sitrep-39-covid-19.pdf?sfvrsn=5bbf3e7d_4

3. T.C Sağlık Bakanlığı covid-19 algoritmaları. Available from: URL: https:// covid19.saglik.gov.tr/TR-66303/covid-19-algoritmalar.html

4. Fang Y, Zhang H, Xie J, Lin M, Ying L, Pang P, et al. Sensitivity of Chest CT for COVID-19: Comparison to RT-PCR Radiology doi:10.1148/ radiol.2020200432

5. Cao Y, Li Q, Chen J, Guo X, Miao C, Yang H, et al. Hospital Emergency Management Plan During the COVID-19 Epidemic. Acad Emerg Med 2020;27:309-11.

6. Sampson CS. Adaption of the emergency department decontamination room for airway management during COVID-19. Am J Emerg Med 2020;38:1531-2.

7. https://epiguard.com/products/ 